\section{APPLICATION OF GENETICS TO PLANT AND ANIMAL BREEDING}

THE Genetical Society held a symposium on the "Application of Genetics to Plant and Animal Breeding" in London on April 13. The president, Dr. C. D. Darlington, in opening the meeting, said that genetics owes a debt to plant and animal breeding both for its foundation and its development. If the purpose of agriculture in the future is to be the highest production, genetics will have the opportunity of repaying this debt. The object of the symposium was to discuss whether genetics has the capacity to do so.

Mr. M. B. Crane, dealing with fruit and forest tree breeding, said that the production of new varieties, and the maintenance and efficient use of old ones, are problems within the scope of our present genetic knowledge. The first essentials for improvement are a knowledge of modern techniques and of the variation, relationship and distribution of the plants and trees within the different groups. Without this knowledge the breeder would often be working in the dark and be likely to follow some of the old traditions, such as breeding from the best for the best, often to find that this does not work.

The cost of fighting the diseases and pests of fruit, as of other crops, can be largely saved by the establishment of resistant and immune forms, so far attempted only on a small scale. Many crops are susceptible to injury by the sulphur, copper and other drugs used to combat diseases. It is known that immunity to this injury is often heritable. Advantage is likely to be obtained by the replace. ment of continuous vegetative propagation by sexual propagation. The devastation wrought by virus disease on the growth and yield of raspberries and strawberries, and the common freedom of seedlings from serious infection for a profitable time might be turned to account. The uniformity of healthy clonal reproduction would not be surpassed, but, in the clone, virus gives rise to great variability and decline in yield, quality and growth.

In apples and pears about a third of the varieties are triploids. This means that they have been favoured by selection. In the past we have had to depend on their spasmodic occurrence. In pears triploid families can now be raised at will, and the breeding and induction of tetraploids is likely to give new forms of outstanding value. To get the best from new polyploid fruits, new polyploid root-stocks might have to be made to fit them. In addition to old varieties, new wild stocks of useful species should be collected and established for the breeders' use, to introduce frost and disease resistance and high nutritive value and to maintain hybrid vigour and variability.

In our farm and garden crops selection and breeding have given us many improved forms which have long ago displaced most of the original wild forms from cultivation. In Great Britain, practically no such improvement has been made or even attempted with forest trees. It seems to be assumed that with forest trees technique would be difficult, and selection and breeding work inevitably prolonged. In the United States and in Sweden, however, both selection and breeding of forest trees have been carried out with decisive results in a short time. Selection for growth and quality has been effective, and important characters such as frost resistance and rapidity of growth have been combined by hybridization. The efficiency of new afforestation programmes will depend on the use made of genetics.

Prof. H. G. Champion indicated the great scope for the practical application of the genetical knowledge which can be gained about our important forest trees. He said it is exceptionally wide in Great Britain owing to the general reliance on plantations for regenerating or creating forests, and to the widespread use of exotic species. The consequences of mistakes made in selection of the stock used in any locality will carry on for at least a tree generation. Relatively little intensive research has been done on forest trees; but there is ample evidence that the majority of the factors most important to foresters both in growing their forests and in the quality and quantity of their final yield vary to an important extent with genetic constitution.

The older work has been mainly the comparison in various localities of results obtained with collections of seed made in different parts of the geographic range of the species concerned. This work has demonstrated that differences often occur so marked that on the right choice might depend outstanding success or complete failure. Such studies cover all the common species but have given particular attention to Pinus sylvestris. More recently, attention has been paid to controlled pollination both to ensure homogeneity and to study the results of crossing both within a species and between species. Examples of commercially important hybrids and polyploids are available, notably with Larix and Populus.

Genetical research on forest trees and the practical application of results present special difficulties as compared with similar work on other plants. These have probably been over-emphasized, but are the main cause of the relative neglect under which the subject has suffered at the hands of botanists and practical foresters. These difficulties were briefly reviewed. For research, they derive from the large size of the tree unit, the late maturation and inaccessibility of the flowering branches, and the fact that growth in crops is essential for proper assessment. In application of results, these same hindrances are involved and, furthermore, most forest trees cannot easily be multiplied vegetatively. Considerable progress has already been made in surmounting these obstacles and it is thought that many of the problems should be capable of solution; organized attack with official support is strongly to be recommended.

Prof. T. J. Jenkin explained the conflict that existed before genetic methods were applied to grass breeding. The grassland farmer wanted a permanent sward, and the seedsman selected for abundant seed ; but the two are incompatible. More recent work has been directed mainly towards improvements in yield, particularly in the form of hay, and it was not at first realized that practical grass-breeding involves at least two distinct problems, of which the simpler and less important is this increased hay yield. The second, and the more important under Welsh conditions, is the production of persistent and productive strains that will stand continuous grazing over a period of years. The grasses, even apart from their heterozygosity, are not good subjects for formal genetical studies (except where defective seedlings are concerned) because they present very few characters that can be easily observed in the mature plant. The important characteristies such as growth habit, tillering capacity, persistence of the individual plant, 
time of flowering, growth and productivity and so on are presumably extremely complex, and a satisfactory method of studying them is greatly needed. At the same time, the grass breeder should not completely neglect formal genetics, and particularly should a general genetical survey of plant material be made if only in order that a more definite estimate of the total heterozygosity of the various species might be made.

Dr. G. D. H. Bell pointed out that the most obvious contribution which genetics can make to the breeding of crop plants is to improve the efficiency of selection of parental material, and of the desired genotypes in mixed or hybrid populations. Many of the attributes which determine the agricultural and economic value of a crop are of a complex nature, showing the general characteristics associated with quantitative or polygenic inheritance, and improvement depends on the accurate genotypic selection of the most desirable combinations of these attributes. Therefore, although more knowledge is necessary concerning the genetics of quantitative characters in general, and of certain 'breeding characters' in particular, it is necessary to realize that the latter require careful definition and resolution in relation to their morphological and physiological components before genetic analysis is attempted.

Where crop improvement is dependent largely on hybridization, its efficiency is dependent, first, on the correct choice of the parental material, and it is essential to have knowledge concerning the breeding value of the material available, and the possibilities of combining characters which might show physiological incompatibility. This is a matter of considerable importance in any scheme of hybridization which involves a progressive synthesis of components affecting the expression of a complex character.

Accurate genetical investigation is dependent on the reasonably easy recognition of genotypes and genotypic variation. The difficulty in plant breeding which involves field selection is the assessment of the individual, or of a small progeny, when several characters are concerned and each is affected to varying degrees by the environment. Attempts have been made to develop selection indices for improving the efficiency of field selection; but there are considerable difficulties in the application of such methods to any reasonable amount of breeding material. However, it is in relation to the above considerations that any further contributions on the part of genetics to plant improvement must be considered.

Dr. K. Mather remarked that the progress of genetics has not yet led to the marked advances in plant and animal breeding which has been so confidently expected in the past. He pointed out that it will be necessary to determine which branches of genetical study are directly concerned with the problems of breeding, and deliberately to foster investigations of these kinds. They must aim primarily at increasing the precision with which the tools of the breeder-selection, adjustment of the mating system, and adjustment of population sizecan be used to manipulate the heritable variation which constitutes his raw material.

The first necessity is a knowledge of the type of inheritance involved in breeding for any particular character, and this is not yet available in all cases. Where inheritance is simple, depending on major genes, genetics can already supply the information necessary for estimating the progress which might be expected, for determining how to plan the breeding programme, and for calculating its magnitude. The great majority of characters involved in breeding programmes, however, show polygenic variation, depending on many genes having srnall, similar and supplementary effects. Such genes determine a type of inheritance different from and more complex than that depending on major genes. Furthermore, they cannot be individually identified owing to the masking effects of one another and of non-heritable variation. Genetics has in the past offered little help in handling polygenic variation; but recent investigations are changing this situation. Methods are now available for separating and estimating, from $F_{2}$ and $F_{3}$ data, the non-heritable, fixable genetic, and unfixable genetic, parts of the variation in crosses, and so of gaining an idea of the progress which can be expected from them. The action of selection on such systems of variation is also keing elucidated, as is the response of variation to changes in mating system. These advances have been made possible by the application of statistical methods developed during the past fifteen years, and further progress in this field will depend on the close cooperation of geneticists, breeders and statisticians.

Dr. Mather concluded by discussing the possibilities of building up new systems of variation through species crossing and polyploidy, and of inducing new and desirable variation by experimental means.

Turning to cattle breeding, Dr. H. P. Donald pointed out that the evolution of breeds is controlled by the isolation and size of populations, random fluctuations in gene frequency, and selection. Isolating factors at work both within and between breeds include pedigree registration, closed herds, attestation, geography and breeding objective. Within breeds, however, the rate at which breeding stock, especially bulls, are exchanged between one partially isolated group and another must reduce the effects of the isolation and prevent the growth of locally adapted types. The small size of many herds retards selection. In one breed, about 70 per cent of the herds are estimated to have fewer than twenty-five calved cows or heifers. The number of bulls in use is correspondingly small, and the result is that the herd is subject to random fluctuations in gene frequency, that the stockbreeder is obliged to purchase bulls, and finds difficulty in discriminating against unsuccessful sires. The constant process of dispersal of established herds and their replacement by new ones results in a herd-age distribution somewhat resembling the age distribution of animals themselves. There are many herds which have had opportunity to practise selection for only three or fewer generations. About 60 per cent of the herds in a sample of 475 herds in one breed of dairy cattle have been breeding pedigree animals for seventeen years or less. This immaturity of so many herds must also markedly reduce the amount of effective selection being practised within breeds.

Dr. A. Walton said the main function of the animal in farming economy is the conversion of available raw materials, unsuitable or less suitable for direct human consumption, into products which can be directly consumed. It follows from this that as techniques of production improve, not only does the standard of the product rise but so also does the standard of nurture of the animals supplying the product. Livestock is improved as a direct result of better nurture. Improvement might be independent 
of any change of genotype, although the expression of the genes might be considerably altered. In the past, improvements due to both nurture and genetic selection have proceeded simultaneously and it is impossible to evaluate either separately. Livestock improvement is not the simple sum of improved nurture plus genetic improvement but is more nearly expressed as the resultant of the two factors acting together. If genetic selection is applied to a heterogeneous population maintained at a constant level of nurture some improvement might result from the isolation and combination of major genes. There will be an approach to homozygosity and genetic stability, and the level of nurture will set a limit to any further improvement. If the standard of nurture of a heterozygous population is raised, there will be increased differentiation of genotypes, and selection (whether conscious or natural) will proceed more rapidly than on a lower plane but eventually the same condition of stability will be reached. By feeding animals individually and successively raising the plane of nurture, and by selecting those genotypes which respond, the breeder directs the evolution of superior strains. In the past, nutritional research and genetics have been carried out in isolation. Livestock improvement requires the combined attention of both nutritionist and geneticist.

Dr. J. M. Rendel argued that, owing to the division which exists between commercial and stud breeding in animal husbandry, attempts to improve stock are handicapped in two ways.

(1) The size of the effective breeding population is reduced to approximately 1,250 males and 30,000 females per breed in sheep, 180 males and 5,000 females in cattle, and 70 males and 1,000 females in pigs, these being the populations required to provide sires for the commercial breeders; the universal introduction of artificial insemination will reduce the size of stud populations, if the present organization is kept, to ridiculously small numbers. In such small populations the variability upon which selection depends is reduced and recombination of genes in any particular way is made more difficult; the comparatively small size of flocks and herds of sheep and cattle may account for the restricted lines along which each breed has been improved as compared to the Rhode Island Red, which, with a prewar population of twenty million, combines good table qualities with a very large egg production.

(2) There is reason to believe that if selection is carried out to produce a given character in two different environments, two different sets of genes will be selected, neither of which would produce the desired result if the environments were interchanged; thus, where stud breeders are selecting in an environment different from the one the commercial farmer will provide, they are selecting animals in a direction not best suited to the commercial breeder. The distinction, therefore, between commercial and stud breeding should go, and populations made up of whole breeds, working under uniform environmental conditions, be treated as one unit for breeding purposes.

Prof. R. A. Fisher said that the production of elite breeding stock is a different matter from its dissemination or its utilization. In the period of modern genetics, the traditional procedure of selective breeding has been shown to be capable of great acceleration by the use of objective tests of performance, developed chiefly abroad. Progeny tests were here included, for they are only performance tests applied to relatives, usually daughters, of the animals selected. Unfortunately, they can only be applied to the minority, the great majority having to be eliminated on other grounds.

It should be remembered in this regard that mothers are as closely related as daughters. The only difference is that there are fewer mothers. The advantage of using daughters for performance tests depends, therefore, on their correct statistical treatment.

Recording societies do valuable work in testing performance in practical conditions of animal husbandry, but the conditions are highly variable. There is need for selective livestock improvement centres equipped to carry out tests with some experimental refinement. These could issue certificates of performance, and should be associated with selective breeding projects (Prof. Fisher personally favouring dual-purpose projects), with the central organization of recording activities, and with artificial insemination units. Artificial insemination alone, however, can do little towards livestock improvement, unless based on the use of objectively tested stock. Price is no criterion.

The genetic personnel available is so limited for any serious programme of livestock improvement that specialization will be essential. The problem of improving the objective tests so far used in respect of precision, for the two objects of $(a)$ assessing the commercial value of a farm animal, and of $(b)$ assessing its breeding value, is too technical and intricate to be added to the responsibilities of the livestock improvement centres. There is need of a single laboratory charged solely with the study of these tests, with the view of increasing their precision in these two respects. In addition to the published literature, it should in time be able to draw valuable data from the experience of carefully planned selective improvement projects carried out with the best available types of livestock.

For the sake of brevity, Prof. Fisher omitted reference to the very extensive, important and successful work carried out in hybrid corn programmes in the United States; as this was referred to in discussion, he added that he regards the experience gained in this field in the last twenty years as of the utmost consequence, especially to animal breeders.

In the discussion, Dr. A. E. Brandt explained that twenty years ago maize yields in the United States were no higher than those produced by the Indians before the discovery of America. Breeding improvement had no more than made up for soil deterioration ; but lately a great change has taken place. From 10 million acres of maize in Iowa in 1933 the yield was 37 bushels per acre; in 1942 it was 62 bushels per acre, both without fertilizers. Two thirds of the increase was due to the use of hybrid seed produced for local conditions.

Touching this question, Dr. S. Ellerton said that breeders would sometimes maintain that a particular crop or animal has been so highly bred that further genetical improvement would be so slight and so difficult as not to be worth while. This was said of maize before the introduction of hybrid combinations of inbred lines. It has been said of cattle in the U.S.S.R. and of cereals in Great Britain. In his opinion, such apparent 'genetical limits' are merely imposed by the shortcomings of current breeding methods and would prove to be false, as was clearly so in maize. In the case of wheat he had some evidence. In 1943 he tested forty-two $F_{2}$ 's involving 
the best British wheat varieties against their parents and established an average increase in the hybrids of 10 per cent in number of ears per plant and $4 \cdot 6$ per cent in weight of grain per ear, a total increase of 15 per cent in yield of grain. Some individual crosses would naturally show more heterosis than others, so that this strongly suggested that wheat could be bred for British conditions with yield increases of 20 per cent at least.

Dr. J. S. Huxley and others stressed the need for physiological and genetical examination of practical breeders' data, which are now available.

Prof. J. B. S. Haldane pointed out the importance of natural selection in domestic plants and animals and of undesirable selection for high seed number, or for longevity; the fallacy of assuming that inbreeding necessarily leads to homozygosis; and the danger of standardized clonal reproduction leading to epidemics.

Mr. W. J. C. Lawrence said that ultimate progress in plant breeding would often depend on the selection for efficiency of specific nutrient intake, for rich soils as well as for poor unbalanced ones. In this regard Dr. G. D. H. Bell discussed the need for combined manurial and variety trials for selection under local and good conditions.

Dr. F. Yates directed attention to the importance of testing new varieties of agricultural crops under a wide range of environmental conditions. Varieties might vary considerably in their reactions to different weather conditions, different soil types and different nutrient supplies in the shape of fertilizers. Thus, for example, one of the biggest factors limiting the yield of cereals in Great Britain is their inability to stand up to high levels of nitrogenous manuring without lodging. Modern developments in the technique of experimental design, in particular the development of factorial experiments, which enable several factors to be tested simultaneously (for example, varieties and different fertilizer components), provided the necessary machinery by which such tests can be efficiently made. It is equally important to carry out the tests at a number of different centres and over a number of years, so as to obtain adequate variation in weather and soil conditions. Any experimental programme of this type nocessarily involves a large number of co-ordinated experiments. The organization required for the efficient execution of such experiments has not yet been fully developed, but there is now good prospect of radical improvement in this respect. It is of the utmost importance that the plant-breeding interests should be adequately represented, and should lend their full support to the development of such a co-ordinated programme.

Dr. Darlington, summing up, said that the papers showed an important contrast in treatment between two levels of breeding practice. On one hand there is the situation where common sense alone will sufficiently indicate the breeding programme in its initial stages. This is particularly true in undeveloped conditions and those where negative selection has been practised. Examples have been described in grasses and forest trees where commercial practice favours quantity of seed rather than quality of fodder or timber, and in cattle-breeding when the breed society, founded to improve cattle, has become organized to prevent improvement, a condition which will obviously be broken down by the spread of artificial insemination. No more economical or fruitful programme of genetical research in cattle-breeding could be suggested than the long-neglected survey of actual breeding practice and performance in Great Britain to-day, the outlines of which were indicated by several speakers. At the other extreme is the situation of the highly developed breeds of poultry and varieties of cereals where maintenance and, still more, improvement demand a skilful combination of elaborate techniques. The statistician is necessary for design and for interpretation, the cytologist for exploration and creation, the geneticist for planning and direction. The discussion was chiefly useful in showing what the different levels of organization are and where each is required.

\section{TUBERCULOSIS AND PULMONARY DISEASE}

A RECENT issue of the British Medical Bulletin (2, No. $2 ; 1944)$ is devoted to pulmonary disease. It also contains two new features: one consists of notes from medical publications which are not classified as journals and the other lists the titles and authors of papers in medical journals published in Great Britain and Northern Ireland.

Dr. P. M. D'Arcy Hart, in a special article on the medical and social aspects of pulmonary disease, deals with tuberculosis and industrial diseases of the lungs. The Committee on Tubereulosis in War-time, set up by the Medical Research Council, reported that the social background of tuberculosis is of primary importance and emphasizes the part played by war-time conditions in the rise of mortality due to tuberculosis which has occurred between 1939 and 1941. Blackout, over-crowding, the movement of populations, destruction of homes by bombing, and the entry into industry of people who are not accustomed to its conditions and fatigue are all factors contributing to this rise. Nutritional deficiency is probably less important in this War than it was during 1914-18, because of our efficient national food policy. But working conditions should be carefully watched, especially those of young adults, who are especially susceptible to tuberculosis. The Committee recommends (1) routine mass radiography and advocates the miniature method pioneered by Abreu in Brazil, priority being given to young adults such as factory employees, medical students, nurses, merchant seamen; (2) special money grants to sufferers for at least a year to enable them to leave work, maintain their own standard of living and that of their families and to undergo treatment; (3) rehabilitation of convalescents and, if possible, their gradual return to work.

The Ministry of Health has already instituted the main recommendations of this report. War-time restrictions, Dr. Hart says, have limited the manufacture and issue of miniature radiography sets, but about half a dozen local authorities have received and are using them, and field trials are being carried out with them by a team appointed by the Medical Research Council. It is hard to understand why the manufacture of these sets should not be a first priority. The Ministry of Health's scheme of financial help is in general operation already. The general policy is one of continued watchfulness and avoidance of complacency which everyone will commend.

The Medical Research Council Committee on 